Check for updates

Cite this: RSC Adv., 2018, 8, 27152

\title{
Uptake and distribution characteristics of the novel fungicide pyraoxystrobin in cucumber plants
}

\author{
Xunyue Liu, (D) $\dagger^{* a}$ Xia Chen, $\dagger^{\text {bc }}$ Xingcheng Ding ${ }^{c}$ and Huiming $\mathrm{Wu}^{a}$ \\ The uptake and distribution characteristics of a novel fungicide, pyraoxystrobin, labeled with ${ }^{14} \mathrm{C}$ on its \\ pyrazol ring, were investigated in cucumber (Cucumis sativus) seedlings. Foliar applied pyraoxystrobin \\ rapidly penetrated the treated leaf and reached a maximum uptake of $68 \%$ after $5 \mathrm{~d}$. The translocation of \\ absorbed ${ }^{14} \mathrm{C}$ in cucumber seedlings was both acropetal and basipetal. However, over $74 \%$ of the \\ absorbed ${ }^{14} \mathrm{C}$-pyraoxystrobin remained in the treated leaves. The order of its distribution in the plant was \\ as follows: treated leaf $>$ stalk above the treated leaf $>$ leaves above the treated leaf $>$ stalk below the \\ treated leaf $>$ leaves below the treated leaf $>$ cotyledon $>$ root. Seedlings grown in soils containing \\ bound residues (BR) of pyraoxystrobin revealed that the BRs were not easily absorbed or translocated by \\ the plant. Soil type had a large effect on root uptake, with the highest uptake among the three tested \\ soils from red clay.
}

Received 15th June 2018 Accepted 24th July 2018

DOI: $10.1039 / \mathrm{c} 8 \mathrm{ra05140b}$

rsc.li/rsc-advances

active ingredient per hectare. ${ }^{11}$ Some pesticides that are applied to the soil, along with their degradation products, are often easily bound to organic components and mineral constituents of the soils through physical and/or chemical interactions, forming the so-called bound residues (BRs). ${ }^{12,13}$ Soil BRs can be released again through the soil microorganism activities and physicochemical processes, and the released compounds may be available for uptake by plants and biotic communities..$^{14}$ Based on the potentially hazardous impact of released BRs from many pollutants, such as atrazine, fenitrothion and tetrabromobisphenol $A,{ }^{15-17}$ it is necessary to gather more information regarding the bioactivity of BRs in the biota.

SYP-3343 is a novel fungicide against Pseudoperonospora cubensis for cucumber, which is an important vegetable for human consumption. Safety assessments must consider the absorption, translocation, release and uptake of BRs by cucumber plants. The environmental behavior of SYP-3343 in soils has been addressed; ${ }^{15,16}$ however, the absorption, translocation, and released BRs of SYP-3343 in plants remain unknown. The objectives of the present study were to evaluate the absorption and translocation of SYP-3343 from (1) foliar applications to cucumber plants and (2) cucumber seedlings grown in soils containing BRs, using the ${ }^{14} \mathrm{C}$ isotopic tracer method under simulated field conditions.

\section{Materials and methods}

${ }^{a}$ School of Agriculture and Food Science, Zhejiang Agriculture and Forestry University, Lin'an, Hangzhou 311300, China. E-mail: lxyue1027.com@163.com

${ }^{b}$ Department of Biotechnology and Biomedicine, Yangtze Delta Region Institute of Tsinghua University, Zhejiang, 314006, China

'Institute of Nuclear Agricultural Sciences, Key Laboratory of Nuclear Agricultural Sciences of Ministry of Agriculture, Zhejiang University, Hangzhou 310029, China

$\dagger$ Contribute equally to this work.

\subsection{Materials}

${ }^{14} \mathrm{C}$ labeled SYP-3343 was synthesized in our laboratory with the help of the ShenYang Research Institute of Chemical Industry in China, ${ }^{17}$ and the chemical structure is shown in Fig. 1. The specific activity was $4.53 \times 10^{8} \mathrm{~Bq} \mathrm{~g}^{-1}$. The radiochemical purity 


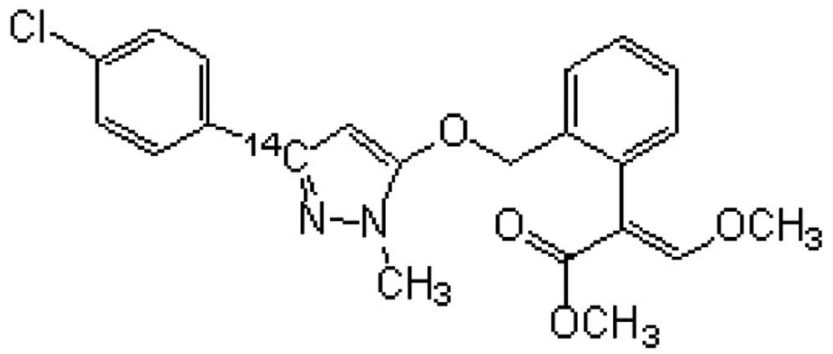

Fig. 1 Structure of ${ }^{14} \mathrm{C}$ labeled SYP-3343.

and chemical purity were both greater than $98 \%$. The scintillation-grade cocktail ingredients 2,5-diphenyloxazole (PPO) and 1,4-di-[2'-(5'-phenyloxazolyl)]-benzene (POPOP) were purchased from Acros Organics (Geel, Belgium). Dimethylbenzene, dichloromethane, acetone, methanol and ethyl acetate were analytical grade. The methanol, acetonitrile and acetic acid used for the chromatographic analyses were of chromatographic grade.

\subsection{Leaf treatment experiment}

Cucumber seeds were soaked in $30{ }^{\circ} \mathrm{C}$ water for $6 \mathrm{~h}$ and then germinated in Petri dishes containing filter papers moistened with distilled water that were incubated in an artificial weather box $\left(28^{\circ} \mathrm{C}\right.$; humidity, $80 \%$, light/dark, $\left.10 \mathrm{~h} / 14 \mathrm{~h}\right)$. The seedlings were sown into flowerpots $(15 \mathrm{~cm} \times 11 \mathrm{~cm} \times 9.5 \mathrm{~cm})$ containing soil ( $\mathrm{pH} 6.95,20.98 \%$ silt, $36.32 \%$ sand and $42.70 \%$ clay contents) and then cultivated under greenhouse conditions (28/ $16^{\circ} \mathrm{C}$, day/night; humidity, $80 \%$; light/dark, $10 \mathrm{~h} / 14 \mathrm{~h}$ ) after they had sprouted two leaves. Plant containers were watered manually as needed during the whole treatment period.

The treatment and analysis methods were modified based on the procedures used by Lycan et al. ${ }^{18}$ Three-leaf stage cucumber seedlings were selected for treatment. The second fully expanded leaf of selected plants was treated with $20 \mu \mathrm{L}$ of $5 \mu \mathrm{g}$ $\mathrm{mL}^{-1} \cdot{ }^{14} \mathrm{C}-\mathrm{SYP}-3343$ solution containing $0.25 \%$ of the surfactant Tween-80 and the radioactive concentration was $83 \mathrm{kBq} \mathrm{mL} L^{-1}$. Prior to treatment, the soil surface of the flowerpots was covered with absorbent papers to prevent the solution from contaminating the soil during the treatment process. After treatment, the seedlings were cultivated under the previous conditions until sampling. Cucumber seedlings were harvested in batches of three plants at $0.25,0.5,1,3,5,8$ and $14 \mathrm{~d}$ after treatment (DAT). The treated leaves were excised from the plants and eluted with methanol for $30 \mathrm{~s}$ at a flow rate of $5.0 \mathrm{~mL} \mathrm{~min}^{-1}$ using a Waters 600E pump (Waters Co., Massachusetts, USA) to remove the unabsorbed SYP-3343. The leachate was directly collected in $20 \mathrm{~mL}$ scintillation vials and mixed with $10 \mathrm{~mL}$ of scintillation cocktail A (5 g PPO, $0.5 \mathrm{~g}$ POPOP, $650 \mathrm{~mL}$ of dimethylbenzene and $350 \mathrm{~mL}$ of glycol-ether). The ${ }^{14} \mathrm{C}$ radioactivity was measured using a liquid scintillation counter (LSC; Wallac 1414, Turku, Finland). Before formal experiments began, ${ }^{14} \mathrm{C}$ SYP-3343 was applied to leaves and after $30 \mathrm{~s}$ sampled to evaluate the efficiency of our leaf-wash method. ${ }^{19}$ The method removed $\sim 98.5 \pm 2.5 \%$ of the unabsorbed ${ }^{14} \mathrm{C}$ SYP3343. The treated plants were divided into seven parts (the roots were washed in advance with tap water to remove soil): treated leaf (TL), leaves above the treated leaf (LATL), stalk above the treated leaf (SATL), leaves below the treated leaf (LBTL), stalk below the treated leaf (SBTL), cotyledon and roots. After drying to constant weights in an oven at $80{ }^{\circ} \mathrm{C}$, all plant parts were combusted using a biological oxidizer (OX-600 Biological Oxidizer, R. J. Harvey Instrument Co., NJ, USA). The duration of combustion was $4.0 \mathrm{~min}$, and the combustion temperature was maintained at $900{ }^{\circ} \mathrm{C}$. Released ${ }^{14} \mathrm{CO}_{2}$, from the sample combustion, was absorbed in $20 \mathrm{~mL}$ of scintillation cocktail B (5 g PPO, $0.5 \mathrm{~g}$ POPOP, $600 \mathrm{~mL}$ dimethylbenzene, $225 \mathrm{~mL}$ glycolether and $175 \mathrm{~mL}$ ethanolamine). The radioactivity was determined using an LSC to quantify the absorbed ${ }^{14} \mathrm{C}-\mathrm{SYP}-3343$ in plant tissues. The recovery efficiency was greater than $90 \%$ as determined by combusting the ${ }^{14} \mathrm{C}$ standard compound. Foliar absorption was calculated by dividing the amount of ${ }^{14} \mathrm{C}$ recovered from the analyzed plant part by the applied ${ }^{14} \mathrm{C}$ activity. Absorption of ${ }^{14} \mathrm{C}$ in cucumber plants was expressed as the percentage of activity in a given tissue over the total absorbed radioactivity. Additionally, two seedlings, which had been subjected to $4.22( \pm 0.01) \times 10^{3} \mathrm{~Bq}$ of applied ${ }^{14} \mathrm{C}$ SYP-3343 were sampled at 8 DAT. The roots were washed with tap water, and the TL was washed with methanol. The whole plants were ovendried at $80{ }^{\circ} \mathrm{C}$ to constant weights. Then, they were wrapped in a layer of preservative film and placed in separate cassettes for two weeks exposure. An imaging analyzer (FUJIFILM BAS-1800, Tokyo, Japan) was used to observe its transport in cucumber seedlings. Non-treated plants were used as controls.

\subsection{Root uptake from soils containing bound residues}

Root uptake from soils containing bound residues was conducted as Han et al. reported. ${ }^{20}$ Brief, three BR-containing soils named (S1, S2 and S3) (physico-chemical property shown in Table 1) were got from our previous study. ${ }^{21}$ The soils were mixed with each corresponding fresh soil to adjust the specific activity to $20.7 \mathrm{~Bq} \mathrm{~g}^{-1} .130 \mathrm{~g}$ of mixed soils were placed in a $200 \mathrm{~mL}$ plastic pot for the cultivation of cucumber plants, and

Table 1 Basic physical and physico-chemical property of the selected soils

\begin{tabular}{llllllr}
\hline No. & Soil type & $\mathrm{pH}$ & $\mathrm{OM}^{a}(\%)$ & $\mathrm{CEC}^{b}\left(\mathrm{meq} .100 \mathrm{~g}^{-1}\right)$ & Silt $(\%)$ & Sand $(\%)$ \\
\hline S1 & Coastal soil & 8.23 & 1.23 & 11.77 & 31.32 & 26.32 \\
S2 & Loamy soil & 6.95 & 2.11 & 10.65 & 36.32 & 20.98 \\
S3 & Red soil & 5.53 & 2.65 & 8.93 & 33.25 & 21.01
\end{tabular}

${ }^{a}$ Organic matter. ${ }^{b}$ Cation exchange capacity. 


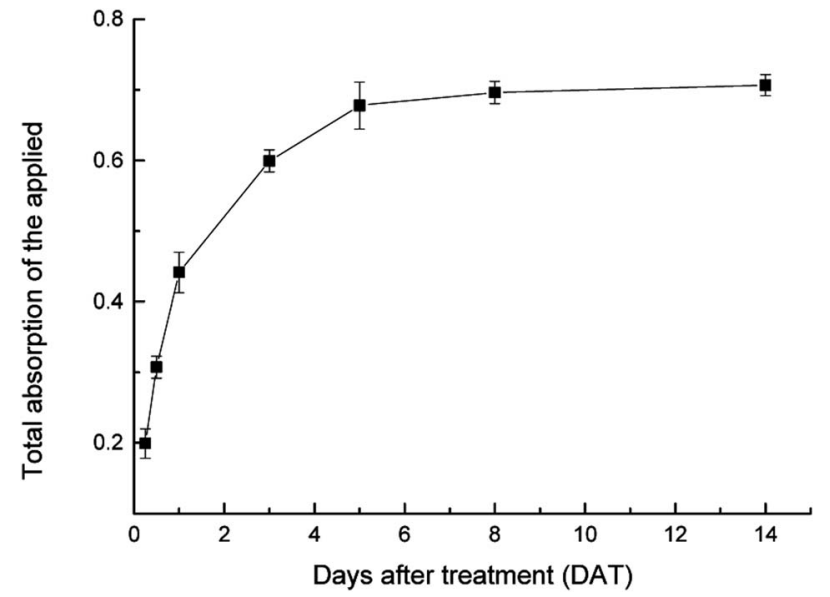

Fig. 2 Total absorption of ${ }^{14} \mathrm{C}$ SYP-3343 in cucumber seedling.

distilled water was added to adjust the soil moisture to $60 \%$ of the water-holding capacity. Five germinated cucumber seeds were sown into each pot, and three replicates were performed for each treatment. Seeds were cultivated in the artificial climate incubator $\left(28 / 16^{\circ} \mathrm{C}\right.$, day/night; humidity, $80 \%$; light/dark, $10 \mathrm{~h} /$ $14 \mathrm{~h}$ ) and irrigated every $2-3 \mathrm{~d}$. The seedlings were sampled after 14 and $21 \mathrm{~d}$. Each seedling was divided into shoots and roots, and the roots were rinsed with tap water. All plant parts were dried to a constant weigh at $80{ }^{\circ} \mathrm{C}$ and combusted in the biological oxidizer. The released ${ }^{14} \mathrm{CO}_{2}$ was absorbed in $20 \mathrm{~mL}$ liquid scintillation cocktail $\mathrm{B}$, and the radioactivity was measured using an ultra-low liquid scintillation spectrometer (ULLSS; Quantulus 1220, Wallac) to estimate the amounts of BR that were absorbed by the cucumber plant at different times. The recovery efficiency of the above combustion procedure was greater than $95 \%$.

\subsection{Statistical analysis}

The ${ }^{14} \mathrm{C}$ radioactivity was calculated by deducting the background ( $20 \mathrm{dpm}$ for ULLSS and $50 \mathrm{dpm}$ for LSC). Each treatment was replicated three times except the autoradiography only did two times. All of the data were analyzed using Origin 7.5 (Microcal Software, Northampton, MA, USA). The standard deviations (mean \pm standard deviation, $n=3$ ) presented in the

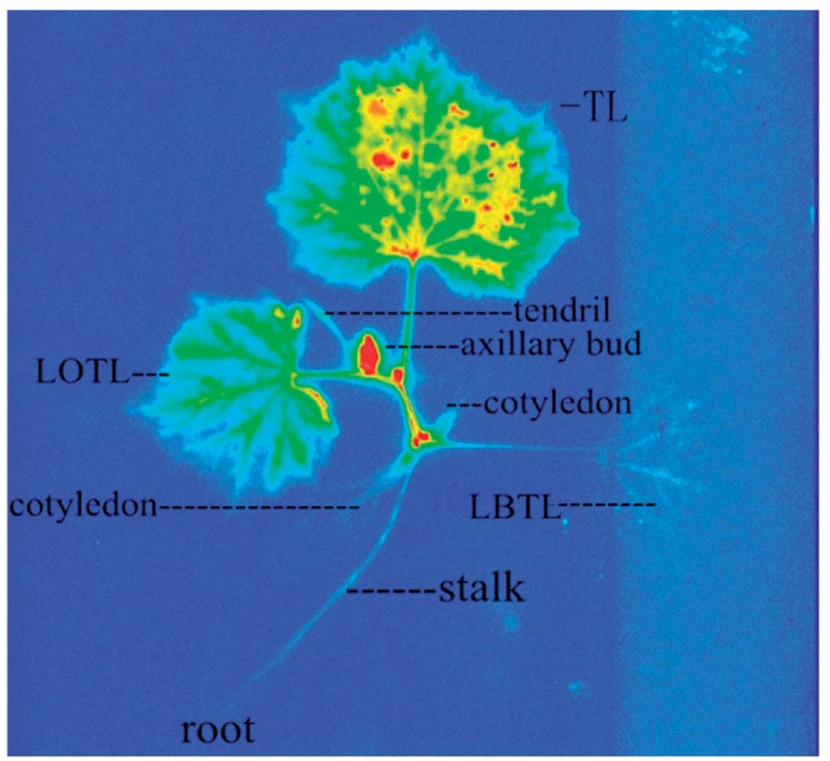

Fig. 3 Autoradiography of the cucumber with ${ }^{14} \mathrm{C}$-SYP-3343 leaf treatment (DAT $=8$ ) (TL: treated leaf; LATL: leaves above treated leaf; LBTL: leaves below treated leaf, red color stands for high ${ }^{14} \mathrm{C}$ concentration, following is yellow, then green).

text were calculated from the repeated measurements. Statistical analysis by one-way analysis of variance (ANOVA) was performed with SPSS 20.0 (IBM Corporation, Armonk, NY).

\section{Results and discussion}

\subsection{Absorption and translocation in cucumber seedlings after leaf treatment}

The ${ }^{14} \mathrm{C}$ radioactivity recovered in TL, LATL, SATL, LBTL, SBTL, cotyledon and root were added together to calculate the total absorption amount in cucumber seedlings. The absorption of ${ }^{14} \mathrm{C}-\mathrm{SYP}-3343$ in cucumber seedlings is shown in Fig. 2. At 0.25 DAT, $20 \%$ of the applied SYP-3343 was absorbed. This increased to $68 \%$ at 5 DAT. However, it then remained at this level until 14 DAT (Fig. 2). Pesticides transfer from leaves into plants owing to diffusion through leaf cuticles and the transpiration of the symplasm. The hydrophilic-lipophilic balance is necessary for germicidal activity, membrane permeability and conductivity. ${ }^{22}$ As reported by Liu et al. ${ }^{21}$ the octanol $/ \mathrm{H}_{2} \mathrm{O}$

Table 2 Translocation and distribution of ${ }^{14} \mathrm{C}$ SYP-3343 in cucumber seedling after leaf treatment (\% of applied) ${ }^{a}$

Days after treatment (DAT)

\begin{tabular}{lccccrrr}
\hline Day & 0.25 & 0.5 & 1 & \multicolumn{3}{c}{} & \multicolumn{2}{c}{} \\
TL & $74.06 \pm 0.09 \mathrm{a}$ & $74.28 \pm 0.13 \mathrm{a}$ & $74.74 \pm 0.12 \mathrm{a}$ & $75.76 \pm 0.07 \mathrm{a}$ & $75.98 \pm 0.18 \mathrm{a}$ & $76.09 \pm 0.11 \mathrm{a}$ & $76.15 \pm 0.12 \mathrm{a}$ \\
LATL & $5.10 \pm 0.14 \mathrm{a}$ & $5.72 \pm 0.18 \mathrm{~b}$ & $5.85 \pm 0.13 \mathrm{~b}$ & $5.89 \pm 0.21 \mathrm{~b}$ & $6.54 \pm 0.12 \mathrm{c}$ & $6.64 \pm 0.24 \mathrm{c}$ & $7.23 \pm 0.22 \mathrm{~d}$ \\
SATL & $6.68 \pm 0.22 \mathrm{a}$ & $6.73 \pm 0.12 \mathrm{ab}$ & $6.81 \pm 0.16 \mathrm{ab}$ & $6.95 \pm 0.18 \mathrm{~b}$ & $7.34 \pm 0.13 \mathrm{c}$ & $7.53 \pm 0.24 \mathrm{c}$ & $7.37 \pm 0.17 \mathrm{c}$ \\
LBTL & $4.20 \pm 0.18 \mathrm{a}$ & $4.09 \pm 0.27 \mathrm{a}$ & $4.03 \pm 0.18 \mathrm{ab}$ & $3.87 \pm 0.11 \mathrm{bc}$ & $3.65 \pm 0.22 \mathrm{c}$ & $3.69 \pm 0.19 \mathrm{c}$ & $3.63 \pm 0.13 \mathrm{c}$ \\
SBTL & $6.62 \pm 0.26 \mathrm{a}$ & $5.66 \pm 0.21 \mathrm{~b}$ & $5.53 \pm 0.17 \mathrm{bc}$ & $5.42 \pm 0.11 \mathrm{c}$ & $4.43 \pm 0.21 \mathrm{~d}$ & $4.32 \pm 0.24 \mathrm{~d}$ & $4.29 \pm 0.22 \mathrm{~d}$ \\
Cotyledon & $0.88 \pm 0.03 \mathrm{a}$ & $0.77 \pm 0.02 \mathrm{~b}$ & $0.76 \pm 0.03 \mathrm{~b}$ & $0.65 \pm 0.01 \mathrm{c}$ & $0.66 \pm 0.01 \mathrm{c}$ & $0.66 \pm 0.02 \mathrm{c}$ & $0.6 \pm 0.01 \mathrm{~d}$ \\
Root & $0.75 \pm 0.02 \mathrm{a}$ & $0.73 \pm 0.01 \mathrm{a}$ & $0.62 \pm 0.01 \mathrm{~b}$ & $0.63 \pm 0.01 \mathrm{~b}$ & $0.62 \pm 0.01 \mathrm{~b}$ & $0.61 \pm 0.01 \mathrm{~b}$ & $0.58 \pm 0.01 \mathrm{c}$
\end{tabular}

${ }^{a}$ Data are the mean of three replications \pm standard error of the mean. Means of plant parts within a row by the same letter are not significantly different according to ANOVA $(P<0.05)$. 
Table 3 The uptake of ${ }^{14} \mathrm{C}$-SYP 3343 BRs in cucumber seedlings grown in different soils (\% of applied $)^{a}$

\begin{tabular}{|c|c|c|c|c|c|c|}
\hline Soil no. & \multicolumn{3}{|l|}{14 DAT } & \multicolumn{3}{|l|}{$21 \mathrm{DAT}$} \\
\hline $\mathrm{S} 2$ & $0.048 \pm 0.003$ & $0.014 \pm 0.002$ & 0.062 & $0.047 \pm 0.002$ & $0.017 \pm 0.002$ & 0.064 \\
\hline S3 & $0.077 \pm 0.002$ & $0.047 \pm 0.002$ & 0.124 & $0.144 \pm 0.001$ & $0.065 \pm 0.001$ & 0.209 \\
\hline
\end{tabular}

${ }^{a}$ Data are means of five replicates \pm standard deviation.

partition coefficient $\log P$ is 3.93 that means ${ }^{14} \mathrm{C}-\mathrm{SYP}-3343$ is a liposoluble pesticide which can permeate membrane epidermal cells and be absorbed by cucumber seedlings. Bromilow et al. reported that the compound transport characters were affect by its $\log P$, when $\log P$ is near 4, the compound will be difficult to migrate neither up nor down. ${ }^{23}$ Our findings here was assistant with this finding.

As seen in Table 2, the TL contained a significantly greater amount of ${ }^{14} \mathrm{C}-\mathrm{SYP}-3343$ (>74.06\%) compared with other parts, which indicated that most of the absorbed ${ }^{14} \mathrm{C}-\mathrm{SYP}-3343$ remained in the TL and could not be easily transported. The rest of the SYP-3343 was transferred to the acropetal (following the xylem transpiration stream from lower to higher in the plant) and basipetal (following the photosynthate transportation in phloem from higher to lower in the plant). However, the acropetal translocation was greater than that of the basipetal, especially by 3 DAT. The LATL (7.23\%) and SATL $(7.37 \%)$ values after $14 \mathrm{~d}$ were approximately two times greater than those of LBTL (3.63\%) and SBTL (4.29\%). The ${ }^{14} \mathrm{C}$ content in root was always less than that in cotyledon within the experimental time.

In the autoradiographs of cucumber seedlings taken at 8 DAT with ${ }^{14} \mathrm{C}-\mathrm{SYP}-3343$, which appears as a bright color, a deeper red indicates that a high ${ }^{14} \mathrm{C}$ concentration existed (Fig. 3). The ${ }^{14} \mathrm{C}$ concentrations in the different cucumber plant parts followed the order TL $>$ SATL $>$ LATL $>$ SBTL $>$ LBTL $>$ cotyledon $>$ root. Thus, the absorption and transportation of ${ }^{14} \mathrm{C}-\mathrm{SYP}-3343$ was confirmed in cucumber plants. The axillary bud appeared to have a high ${ }^{14} \mathrm{C}$ concentration, indicating that SYP-3343 may be transported to cucumber fruit. Further experiments are needed to confirm this finding.

\subsection{Root absorption and translocation in cucumber seedlings grown in soils containing bound residues of ${ }^{14} \mathrm{C}$ - SYP-3343}

To determine the potential release of soil bound ${ }^{14} \mathrm{C}$ SYP-3343 residues and their absorption and translocation in cucumber seedlings grown in the BR-containing soil, cucumber seedlings were divided into two parts: one part contained the stem and leaf, and the other contained the remaining root. Table 3 shows the percentage of ${ }^{14} \mathrm{C}$ radioactivity in each plant part at 14 and 21 $\mathrm{d}$ after the cucumber seedlings had been growing in ${ }^{14} \mathrm{C}$ SYP-3343 BR-containing soil. The ${ }^{14} \mathrm{C}$ could be released from BRs into the root and then transported up to the stems and leaves. The amount of ${ }^{14} \mathrm{C}$ in the stem and leaf section of the plant increased with treatment time. There was a greater ${ }^{14} \mathrm{C}-\mathrm{SYP}-3343$ distribution in shoots than in roots at both 14 and 21 DAT in the three soil types (Table 3 ). The BRs of ${ }^{14} \mathrm{C}$-labeled prometryn, malathion, parathion and carbofuran were more likely to be transported into shoots than that of SYP-3343. ${ }^{24-27}$ However, the uptake percentage for cucumber was very limited, and the maximum amount detected was only $0.21 \%$ at 21 DAT. The interaction between soil and pesticide was complicated. Many factors, such as soil physicochemical properties, microbial community structure and enzymatic activities, play roles in the release of BRs. ${ }^{28}$ During the cultivation period, different soil conditions may have contributed to the different $\mathrm{BR}$ release rates. Much greater amounts of the released ${ }^{14} \mathrm{C}$ in red soil (S3) were absorbed into cucumber seedlings than in coastal soil (S1) and loamy soil (S2).

\section{Conclusions}

The leaf absorption of ${ }^{14} \mathrm{C}$ SYP-3343 into cucumber seedlings was rapid, and the total absorption reached a maximum value of $68 \%$ by 5 DAT. Translocation occurred from the TL to all cucumber seedling parts, and the accumulation was greater in the acropetal than in the basipetal. Foliar applications may affect the cucumber fruit within $5 \mathrm{~d}$. Soil properties can affect the release of the BRs, but less than $0.21 \%$ of the BRs can be taken up through seedling roots. This suggested that the BRs of SYP-3343 in the soil could not be easily transferred into cucumber fruit. More studies should be conducted to determine if SYP-3343 poses a potential risk to the environment and/or human health.

\section{Conflicts of interest}

There are no conflicts to declare.

\section{Acknowledgements}

This work was financially supported by the National Natural Science Foundation of China (No. 11505155) and the Research Development Fund of Zhejiang A \& F University (No. 2015FR013).

\section{References}

1 H. Sauter, W. Steglich and T. Anke, Strobulurins: evolution of a new class of active substances, Angew. Chem., Int. Ed., 1999, 38, 1328-1349. 
2 D. W. Bartlett, J. M. Clough, J. R. Godwin, A. A. Hall, M. Hamer and B. Parr-Dobrzanski, The strobilurin fungicides, Pest Manage. Sci., 2002, 58, 649-662.

3 W. F. Becker, V. G. Jagow, T. Anke and W. Steglich, Oudemansin, strobilurin A, strobilurin B and myxothiazol: New inhibitors of the bc1 segment of the respiratory chain with an e- $\beta$-methoxyacrylate system as common structural elements, FEBS Lett., 1981, 132, 329-333.

$4 \mathrm{H}$. Chen, Z. Li and Y. Han, Synthesis and fungicidal activity against Rhizoctonia solani of 2-alkyl(alkylthio)-5-pyrazolyl1,3,4-oxadiazoles(thiadiazoles), J. Agric. Food Chem., 2000, 48, 5312-5315.

5 H. J. Park, K. Lee, S. J. Park, B. Ahn, J. C. Lee, H. Y. Cho and K. I. Lee, Indentification of antitumor actitumor activity of pyrazole oxime ethers, Bioorg. Med. Chem. Lett., 2005, 15, 3307-3312.

6 N. Fisher and B. Meunier, Re-examination of inhibitor resistance conferred by Qo-site mutations in cytochrome b using yeast as a model system, Pest Manage. Sci., 2005, 61, 973-978.

7 U. Gisi, H. Sierotzki, A. Cook and A. Mccaffery, Mechanisms influencing the evolution of resistance to Qo inhibitor fungicides, Pest Manage. Sci., 2002, 58, 859-867.

8 M. Li, C. L. Liu, J. C. Yang, J. B. Zhang, Z. N. Li, H. Zhang and Z. M. Li, Synthesis and biological activity of new (E)-a(Methoxyimino)benzeneacetate derivatives containing a substituted pyrazole ring, J. Agric. Food Chem., 2000, 58, 2664-2667.

9 W. Z. Li, Development of pyraoxystrobin(SYP-3343) 20\% oil dispersion, Agrochemicals, 2008, 47(7), 489-491.

10 Z. J. Fan, H. K. Zhang, L. Ma, X. F. Liu, J. Y. Chen and C. L. Liu, HPLC analysis of novel fungicide SYP-3343, J. Sichuan Norm. Univ., Nat. Sci., 2008, 31, 358-360.

11 M. Li, C. L. Liu, L. Li, Z. M. Li, Z. N. Li, H. K. Zhang and L. Chen, Design, synthesis and fungicidal activity of SYP3343, Proceedings of $7^{\text {th }}$ Chinese annual meeting for innovative pesticide, 2009, pp. 242-246.

12 B. Gevao, K. T. Semple and K. C. Jpnes, Bound pesticide residues in soils: a review, Environ. Pollut., 2000, 108, 3-14.

13 D. Barraclough, T. Kearney and A. Croxford, Bound residues: environmental solution or future problem?, Environ. Pollut., 2005, 133, 85-90.

14 Z. J. Li, J. M. Xu, A. Muhammad and G. R. Ma, Effect of bound residues of metsulfuron-methyl in soil on rice growth, Chemosphere, 2005, 58, 1177-1183.
15 X. Y. Liu, X. Chen, Q. F. Ye and X. C. Ding, Fate characterization of a novel fungicide SYP-3343 in Chinese soils, Prog. Environ. Sci. Technol., 2011, 3, 222-227.

16 X. Y. Liu, X. C. Ding, X. H. Xu and X. Chen, Effect of different environmental factors and fungicide dosage on the residual of SYP-3343, J. Nucl. Agric. Sci., 2012, 26, 348-351.

17 X. Y. Liu, Q. F. Ye, D. L. Kan, Z. Zhang and X. C. Ding, Synthesis of carbon-14 labeled ppyraoxystrobin, a novel fungicide, J. Labelled Compd. Radiopharm., 2011, 54, 780782.

18 D. W. Lycan and S. E. Hart, Foliar and root absorption and translocation of bispyribac-sodium in cool-season turfgrass, Weed Technol., 2006, 20, 1015-1022.

19 S. D. Askew and J. W. Wilcut, Absorption, translocation, and metabolism of foliar-applied CGA 362662 in cotton, peanut, and selected weeds, Weed Sci., 2002, 50, 293-298.

20 A. L. Han, L. Yue, Z. Li, H. Y. Wang, Y. Wang, Q. F. Ye, L. Lu and J. Gan, Plant availability and phytotoxicity of soil bound residues of herbicide ZJ0273, a novel acetolactate synthase potential inhibitor, Chemosphere, 2009, 77, 955-961.

21 X. Y. Liu, X. Chen, H. Y. Wang, T. L. Yang, Q. F. Ye and X. C. Ding, Dynamic characteristics of the novel strobilurin fungicide in aerobic soils, J. Agric. Food Chem., 2014, 62, 3343-3347.

22 L. Edgington, Structural requirements of systemic fungicides, Annu. Rev. Phytopathol., 1981, 19(1), 107-124.

23 R. H. Bromilow, K. Chamberlain and A. A. Evans, Physicochemical aspects of phloem translocation of herbicides, Weed Sci., 1990, 38(3), 305-314.

24 F. Ghezal, M. Miloudi, M. Bennaceur and S. Zayed, Behaviour of ${ }^{14} \mathrm{C}-$ Malathion in north African Soils, Analyst, 1997, 122(8), 859-862.

25 S. U. Khan, Plant uptake of unextracted (bound) residues from an organic soil treated with prometryn, J. Agric. Food Chem., 1980, 28, 1096-1098.

26 J. K. Lee, K. S. Kyung and W. B. Wheeler, Rice plant uptake of fresh and aged residues of carbofuran from soil, J. Agric. Food Chem., 1991, 39(3), 588-593.

27 S. U. Khan, Bound pesticide residues in soil and plants, Residue Rev., 1982, 81, 1-25.

$28 \mathrm{~J}$. Dec and J. M. Bollag, Microbial release and degradation of cathecol and chloroph-enols bound to synthetic humic acid, Soil Sci. Soc. Am. J., 1988, 52, 1366-1371. 